\title{
A Novel Method for Producing Sintered Burdens to Meet the Required Specifications of the Blast Furnaces in (HADISOLB) Company
}

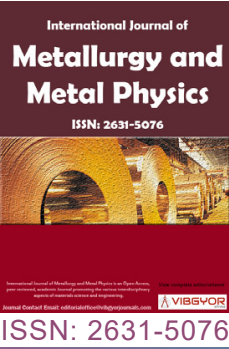

\section{Elsayed MA Rassoul ${ }^{1,2}$ and Roshdy Abdel Rassoul ${ }^{*}$}

\author{
${ }^{1}$ Faculty of Engineering, Mansoura University, Egypt \\ ${ }^{2}$ Member, American Institute of Mining, Metallurgical, and Petroleum Engineers (AIME), USA \\ ${ }^{3}$ Arab Academy for Science \& Technology, Alexandria, Egypt
}

\begin{abstract}
A novel method based on blending El-Bahareya ores together with the highly rich in iron- and impuritiesfree wastes is proposed.

Several pilot scale experiments were performed in HADISOLB Company, where different weight ratios of waste and El-Bahareya ores were mixed, then sintered. The chemical composition, physical and mechanical properties of the produced sinter were determined for each set of experiments. As a result, the validity of this novel method was proved.

The novel method is simply to prepare a suitable mix by blending different weight ratios of El-Bahareya ores and the W.M. to achieve the following targets: 1) An increase in the total iron content of the charge, 2) A decrease in $\mathrm{MnO}$ and $\mathrm{Cl}$ - contents in the iron bearing material, 3) A prolongation of the lifetime of ElBahareya mines and in the limestone quarry in Bani-Khaled, 4) Prolongation in the lifetime of the sintering tray due the decrease of corrosion, and 5) To achieve better economic indices in all the related processes.
\end{abstract}

\section{Introduction}

Sintering of iron ore has been extensively investigated to get better insight into the process [1-5], including study of the use of pellets, sinter, and nut coke charges [6-8], thermodynamic analysis $[9,10]$, and measurements and characterization $[11,12]$.

Relatively high content of $\mathrm{NaCl}$ in the Ironbearing material is considered a threatening factor in the blast furnace process, while that of $\mathrm{MnO}$ is only considered as a threatening factor when we come to the stage of steel production.
The presence of relatively high content of alkalis in the blast furnace burden (sinter) creates a lot of problems [13-15], such as:

a) Formation of scaffolds and scaps on the furnace lining, which reduces its useful volume.

b) Excessive coke disintegration, which leads to higher coke consumption.

c) Enhances the swelling properties of the iron-bearing materials, which lowers the permeability inside the furnace.

d) Shortens the lifetime of the furnace lining.

*Corresponding author: Roshdy Abdel Rassoul, Arab Academy for Science \& Technology, Alexandria, Egypt

Accepted: August 10, 2021; Published: August 12, 2021

Copyright: (c) 2021 Rassoul EMA, et al. This is an open-access article distributed under the terms of the Creative Commons Attribution License, which permits unrestricted use, distribution, and reproduction in any medium, provided the original author and source are credited.

Rassoul and Rassoul. Int J Metall Met Phys 2021, 6:070

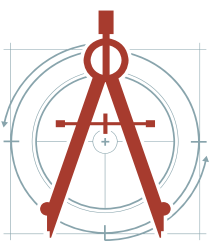


e) Formation of alkali cyanides causing toxic wastes and pollution problems.

It is well known that the alkali content in the last furnace burden at HADISOLB (Helwan) is quite high compared to other steel plants in many countries.

The circulation of alkalis inside the blast furnace deteriorates its performance. It is within the temperature region $700-1200{ }^{\circ} \mathrm{C}$ that alkalis can be expected to exert their greatest influence on burden materials and refractories [13].

The Egyptian Iron and steel company (HADISOLB) depends for its pig-iron production on the sintering of El-Bahareya ores, whose iron content is $<50 \%$, beside the following impurities: $\mathrm{MnO}>2 \%$ and chlorides $>0.6 \%$. The impurities cause several problems successively in the sintering, the blast furnace and the steel making operations.

Meanwhile, in Egypt there are four steel making companies using the direct reduction (DR) route, and are suffering from the accumulation of the highly rich in iron $>67 \%$ and of almost zero impurities waste. The weight of the wastes from the four companies is about one million tons/year, which can be considered as a virtually high rich and highly pure iron oxide mine.

The integrated iron and steel company HADISOLB - at Helwan, Egypt, adopts the sintering -Blast furnace - BOF route to produce pig iron and steel. HADISOLB uses local iron ore located in ElBahareya oasis, which contains a relatively low iron content $(\mathrm{Fe}<50 \%)$, high manganese ( $\mathrm{MnO}>$ $2.5 \%$, and high chlorides $\left(>0.15 \% \mathrm{Cl}^{-}\right)$. The head of the iron and steel company, HADISOLB, had submitted a memorandum in which he stated that the results of the performed experiments in the first field stage of operation proved that HADISOLB will never achieve its designed capacity stated unless the company achieves a way to get rid of the threatening impurities, such as high $\mathrm{Cl}^{-}$and $\mathrm{MnO}$ contained in El-Bahareya iron ores, which is the only economically available iron ore for HADISOLB [16].

On the other hand, there are four integrated steel companies in Egypt which adopt the gaseous reduction route -DR-, and suffer from their accumulated wastes which contain $\sim 67 \%$ iron and almost zero\% $\mathrm{MnO}$ and chlorides in the form of oxide fines and sludge which are as by-products in the stage of the sponge iron production [17]. Figure 1 shows the highly rich iron oxide wastes in the back yard of EZDK steel company in Alexandria, Egypt. Its annual formation as W.M. from the four D.R. companies is estimated to be about one million tons.

Based on the above facts a novel idea was illuminated; it is simply to prepare a suitable mix by blending different weight ratios of El-Bahareya ores and the W.M. to achieve the following targets [18-20]:

1. An increase in the total iron content of the charge.

2. A decrease in $\mathrm{MnO}$ and $\mathrm{Cl}^{-}$contents in the iron bearing material, used in the blast furnace burden.

3. A prolongation of the lifetime of El-Bahareya mines and in the limestone quarry in BaniKhaled.

4. Prolongation in the lifetime of the sintering tray due the decrease of corrosion.

5. To achieve better economic indices in all the related processes.

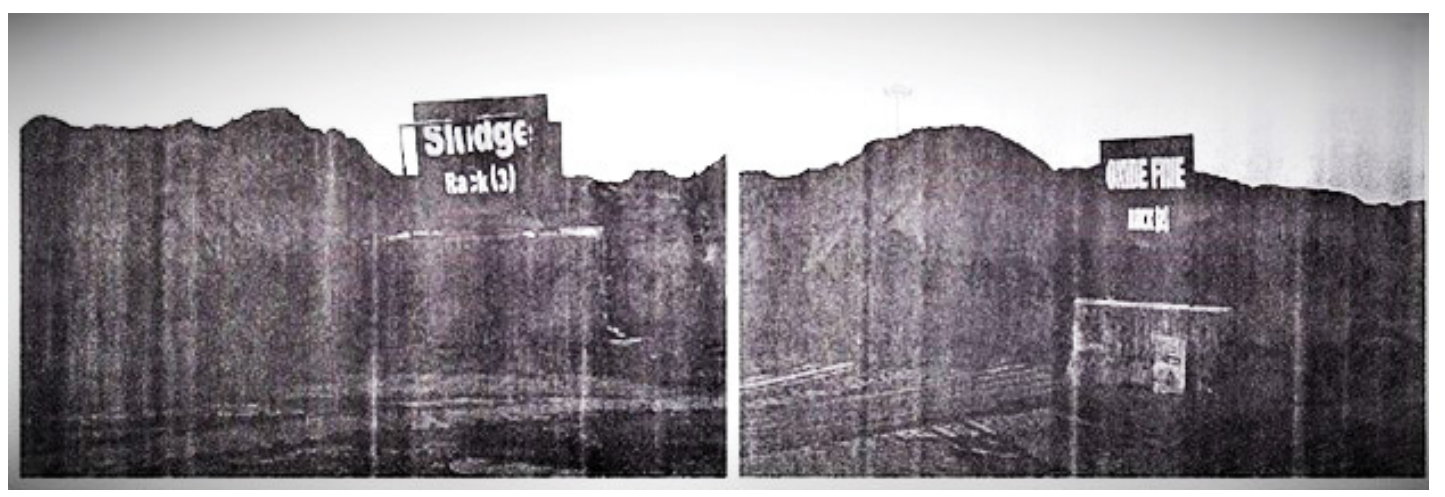

Figure 1: Highly rich iron oxide wastes in the EZDK steel company. 


\section{Materials and Experiments}

HADISOLB is facing nowadays a big problem which could be expressed as:"to be or not to be!" [21].

It adopts as an integrated company the sinteringBlast furnace-BOF route which necessitates from the first beginning to have a high-quality iron ore to produce high quality sinter ... and so on, and thus the highest economic indices for each of these steps will be achieved $[18,22,23]$. The sintering charge usually includes, beside the iron ores, the required amounts of L.S. as a flux, coke and water to produce sinter of a specific composition and quality $[24,25]$.

As a matter of fact, El-Baharey iron ores with all its handicaps, is the only practically available iron bearing material that HADISOLB can get. Meanwhile the head of HADISOLB had previously stated in his memorandum that unless the company finds a way to get rid of the threatening impurities, such as chlorides and $\mathrm{MnO}$, contained in El-Bahareya ores; HADISOLB will never be able to achieve its designed capacity. And thus, getting rid of the effect of these threatening impurities will be the aim of this investigation [17].

\section{Materials}

El-Bahareya iron ores: El-Bahareya iron ore deposits in El-Gedida region became since it was discovered the only iron ore used in HADISOLB Company. It is distributed in three localities. The detailed composition of the three localities is given in Table 1 [26].

Blending of ores from the three localities should lead to the specifications previously agreed upon, in which $\mathrm{Fe} \%$ should be $>51 \%$ and $\mathrm{Cl}^{-}$should be $<0.6$ and $\mathrm{MnO}$ should be $<2.4$ However, after 40 years of exploitation, El-Bahareya mines cannot anymore fulfill such obligations. The iron content in

Table 1: Chemical composition of iron ores in the three localities [26].

\begin{tabular}{|c|c|c|c|c|c|c|c|c|c|c|c|c|}
\hline Locality & $\mathbf{M}$ & FeO\% & $\mathrm{Fe}_{2} \mathrm{O}_{3}$ & $\mathrm{SiO}_{2}$ & $\mathrm{Al}_{2} \mathrm{O}_{3}$ & $\mathrm{CaO} \%$ & $\mathrm{MgO} \%$ & $\mathrm{MnO} \%$ & $\mathrm{Cl}^{-} \%$ & $\begin{array}{l}\text { Loss On } \\
\text { Ignition (LOI) }\end{array}$ & Basicity & $\begin{array}{l}\text { Reserved } \\
\text { Million } \\
\text { Tons }\end{array}$ \\
\hline El Plateau & 0.2 & 21.12 & 50.50 & 8.80 & 1.9 & 8.13 & 0.76 & 2.65 & 0.85 & $\ldots$ up to $100 \%$ & 1.00 & 39.60 \\
\hline $\begin{array}{l}\text { West } \\
\text { Valley }\end{array}$ & 0.24 & 21.54 & 43.41 & 9.00 & 2.48 & 10.17 & 0.74 & 2.35 & 0.74 & $\ldots$ up to $100 \%$ & 1.20 & 60.00 \\
\hline N.E. Valley & 0.4 & 23.49 & 48.83 & 9.51 & 2.00 & 11.70 & 0.84 & 2.27 & 0.22 & ... up to $100 \%$ & 1.40 & 11.98 \\
\hline $\begin{array}{l}\text { Total } \\
\text { Reserves }\end{array}$ & & & & & & & & & & & & 111.38 \\
\hline
\end{tabular}

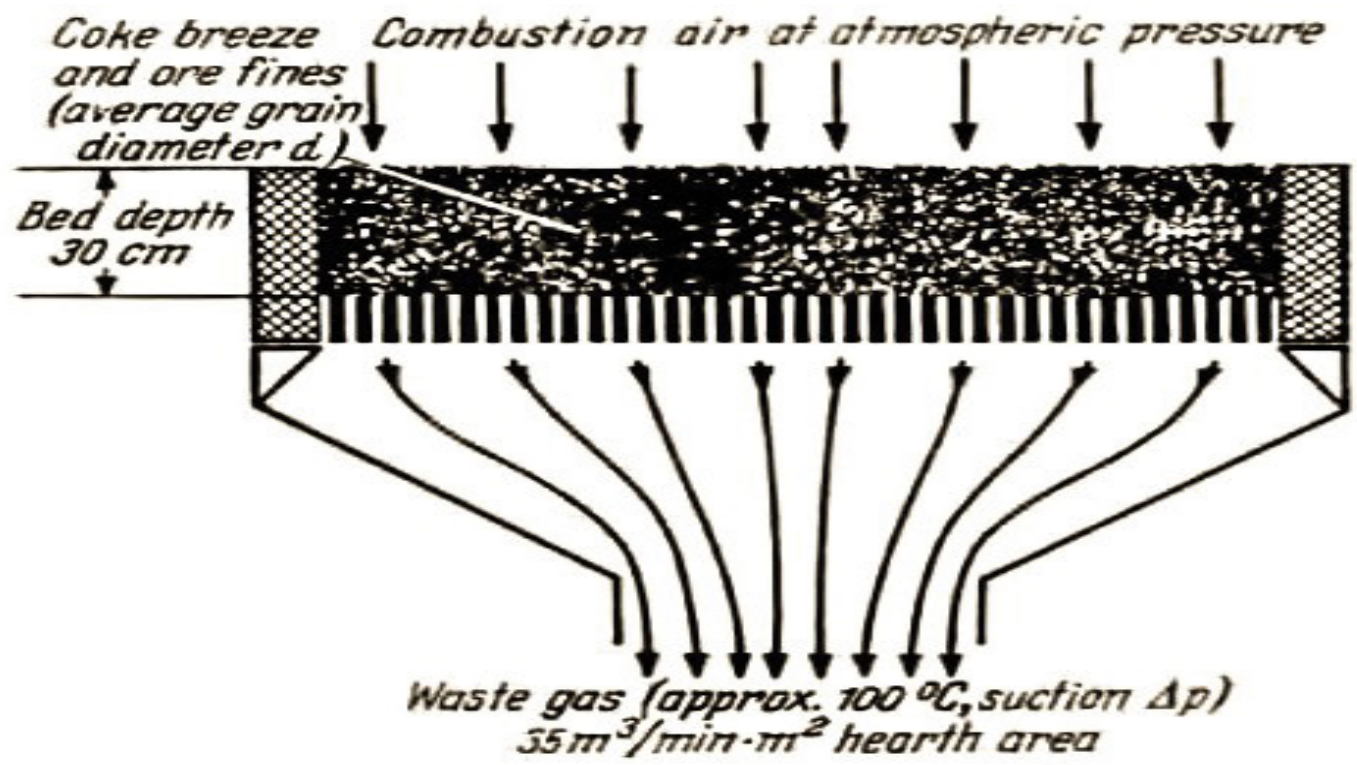

Figure 2: Transferring the well-mixed charge into the sintering crucible [28]. 
the blend is shown in Table 1 and is less than $50 \%$.

Waste materials: By waste material we mean the iron oxide fines and the sludge. The chemical composition of these waste materials, Figure 2, as analyzed by EZDK Company, is given in Table 2 .

This waste obtained from the EZDK Company was delivered to the Egyptian Iron \& Steel Company (HADISOLB), where it was stored in an open space, and different mixtures were prepared from it. The chemical analysis done by the Egyptian Iron \& Steel Company on the samples is shown in Table 3. These were the burdens we used in our experiments, as shown in Table 4.

\section{Experiments}

Bahareya and W.M. of different weight ratios from El-Bahareya and W.M. -fine oxide and sludge- were blended together. Every blend is considered as the only iron-bearing material in the sintering charge. These blends were as shown in Table 5, which shows the chemical composition of the oxide fine and the sludge (The waste materials, as shown in Figure 1).

The sintering charge was prepared by dry mixing predetermined weights of lime stone and coke in order to get sinter with basicity $\left(\mathrm{CaO} / \mathrm{SiO}_{2}\right)$ around one [27].

Mixing the dry blend with limestone and coke was accomplished by spraying water into the charge till the required humidity is obtained. The well-mixed charge then should be transferred into the sintering crucible, as shown in Figure 2 [28], which shows the pilot scale sintering unit, after putting enough coarse sinter on the sintering tray,

Table 2: Chemical composition of the oxide fines and the sludge*.

\begin{tabular}{|l|l|l|l|l|l|l|}
\hline Material & $\mathrm{Fe} \%$ & $\mathrm{CaO} \%$ & $\mathrm{SiO}_{2} \%$ & $\mathrm{Al}_{2} \mathbf{O}_{3} \%$ & $\mathbf{M n O} \%$ & $\mathbf{C l}$ \\
\hline Oxide fines & 67.8 & 0.8 & 1.1 & 0.36 & 0.1 & nil \\
\hline Sludge & 68.1 & 1.2 & 1.8 & 1.16 & 0.2 & nil \\
\hline
\end{tabular}

* Personal communication with EZDK Company.

Table 3: Chemical analysis of EZDK samples done at HADISOLB.

\begin{tabular}{|l|l|l|l|l|l|l|l|l|l|l|l|l|l|}
\hline S. No. & $\mathrm{Fe}$ & $\mathrm{FeO}$ & $\mathrm{SiO}_{2}$ & $\mathbf{C a O}$ & $\mathbf{M g O}$ & $\mathbf{A l}_{\mathbf{2}} \mathbf{O}_{\mathbf{3}}$ & $\mathbf{M n O}$ & $\mathbf{S}$ & $\mathbf{P}_{2} \mathbf{O}_{5}$ & $\mathbf{C l}$ & $\mathbf{B a O}$ & ZnO & T.L. \\
\hline Ore & 65.23 & 20.32 & 3.39 & 1.53 & 0.32 & 0.70 & 0.46 & 0.13 & 0.18 & 0.10 & 0.15 & 0.06 & 1.67 \\
\hline Sludge & 59.69 & 21.35 & 10.52 & 1.42 & 0.27 & 0.65 & 0.48 & 0.12 & 0.21 & 0.07 & 0.10 & 0.06 & 4.31 \\
\hline
\end{tabular}

\section{Increase in Production}

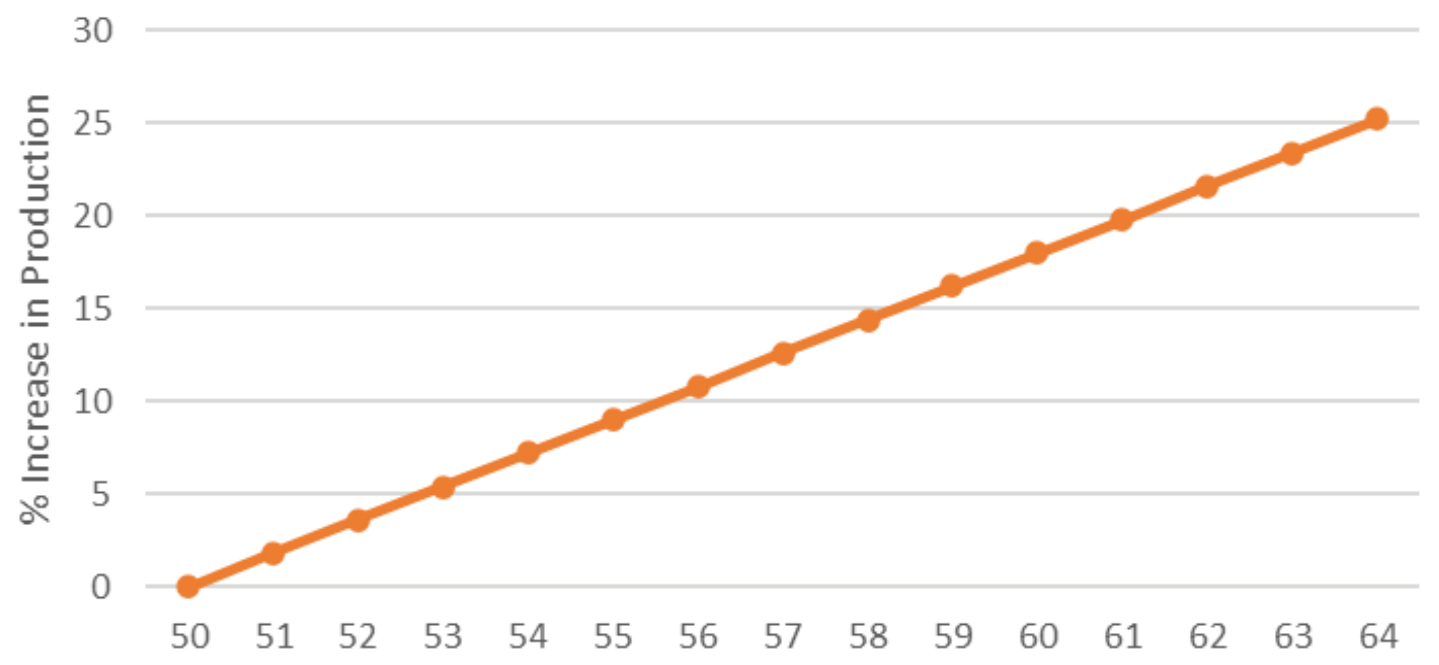

Increase in iron \%

Figure 3: Highly rich iron oxide wastes in the EZDK steel company. 
and a thin layer of fine coke should be added on the surface of the charge in order to initiate the combustion, and for the sintering process to begin.

In Table 4, the average chemical composition and the drum test for all sinters produced using blends of different ratios are given.

\section{Results and Discussion}

One can come to the following conclusion that each $1 \%$ rise in the Fe content in the charge:

1. Will lead to a rise in the productivity of the blast furnace by $1.8 \%$, as shown in Figure 3 .

2. Will lead to a decrease in the coke consumed by $1.1 \mathrm{~kg} /$ ton of Pig iron, as shown in Figure 4 .

3. Will lead to a reduction in the slag which is reflected on the consumption of L.S. and a prolongation of the lifetime of the L.S. quarries in Bani-Khaled.

4. Blending El-Bahareya ores with the highly rich W.M. in iron will lead to the prolongation of the lifetime of El-Bahareya mines. The prolongation of the lifetime of the mines is of course proportional to weight fraction of the W.M. in the blend, as shown in Figure 5.

5. The decrease in the MnO content will be positively reflected on the productivity of the oxygen converters, i.e. the number of heats/ day will increase.
In Table 4, the average values for both the chemical composition and that of the drum test for all sinters are given.

Figure 6 shows the decrease in $\mathrm{Cl}^{-} \%$ and $\mathrm{MnO} \%$ as the blending ratio is increased, plotted from the data of Table 4.

As a matter of fact, any increase in the iron content of the charge, beside the decrease in the threatening impurities, specially the halides, will be strongly reflected on the economic indices of all the production processes, and according to the data provided by HADISOLB.

The results illustrated in Table 4 indicate that the sinter the blend of Experiment no. 8 (30\% ore and $70 \%$ waste) is the best blend, since it has the best mechanical properties of all blend \{drum test $(-5 \mathrm{~mm} \%)\}$.

\section{Conclusions and Recommendations}

Besides, several other benefits were accomplished, such as:

1. Extension of the lifetime of El-Bahareya mines.

2. Evaluation of the expected increase in the production indices in both the sintering, blast furnace, and steel making operations.

3. An extension in the lifetime of the tray of sintering machine due to the reduction of

\section{Savings in Coke Consumption}

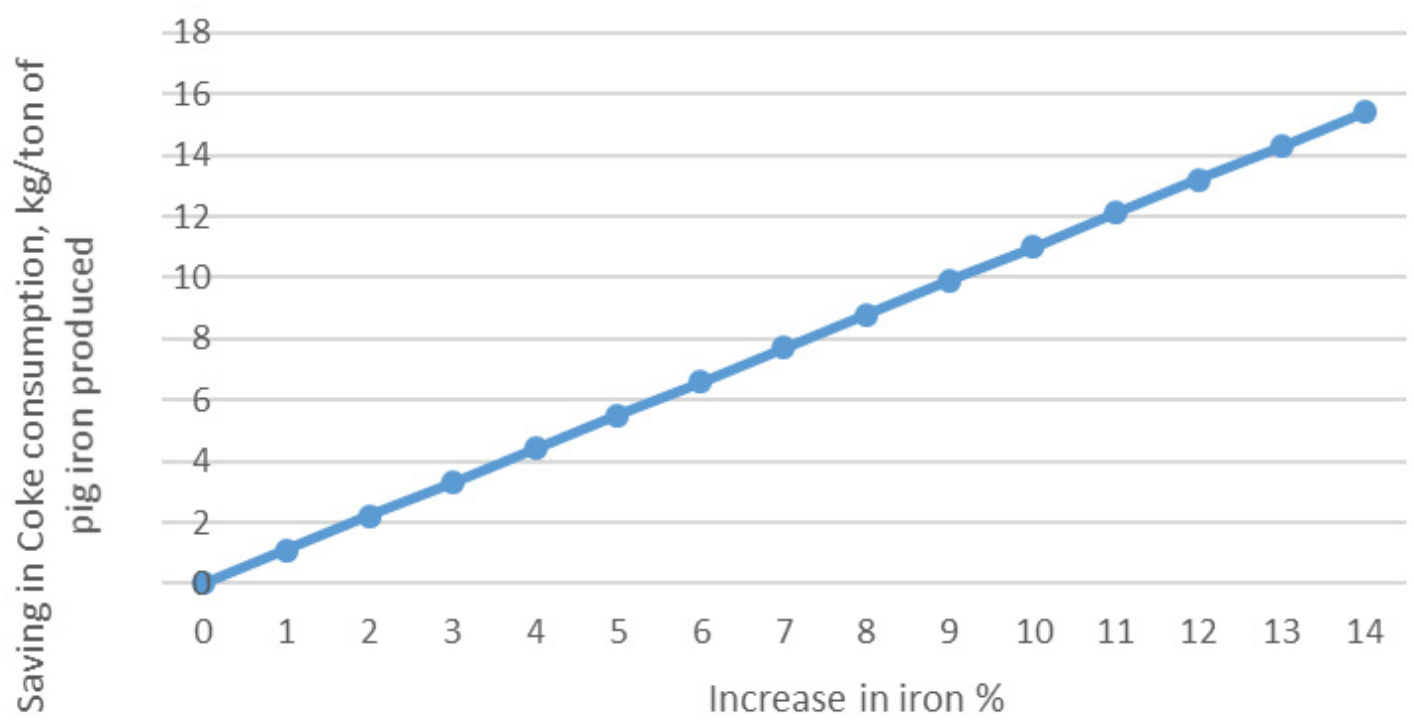

Figure 4: Highly rich iron oxide wastes in the EZDK steel company. 


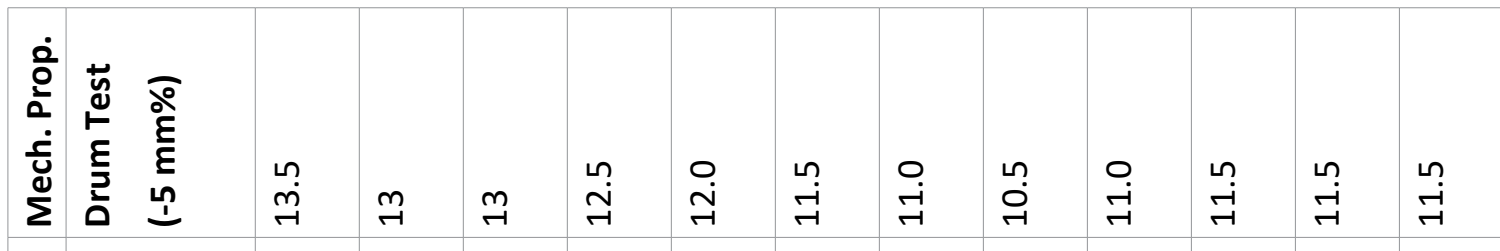

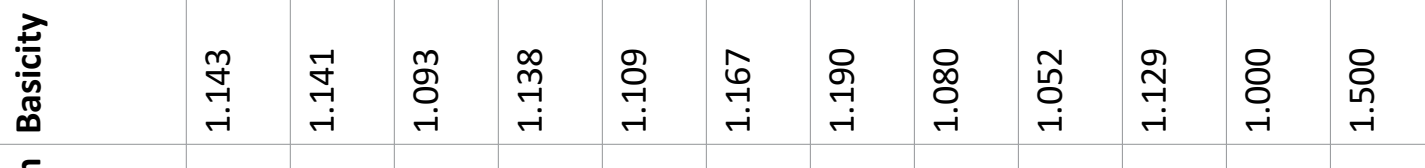

ఏे̀

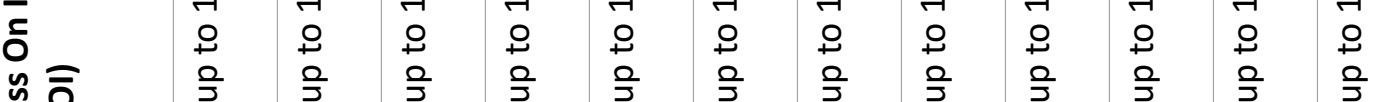

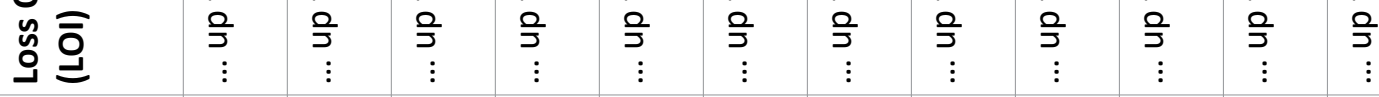

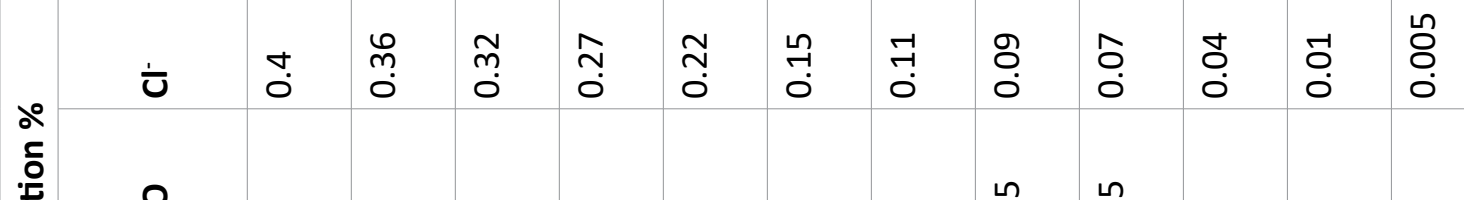

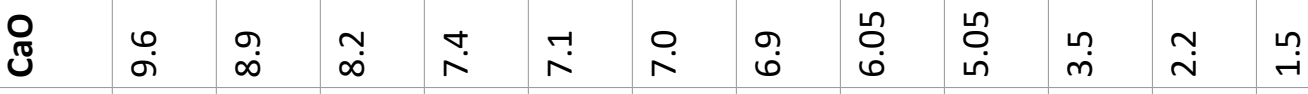

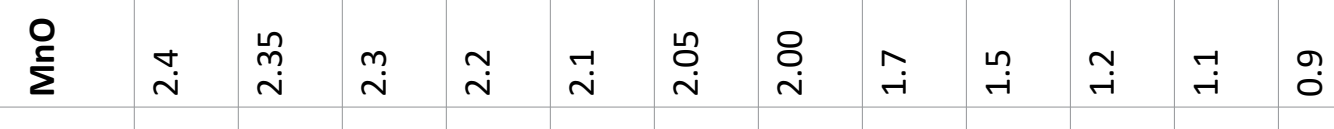

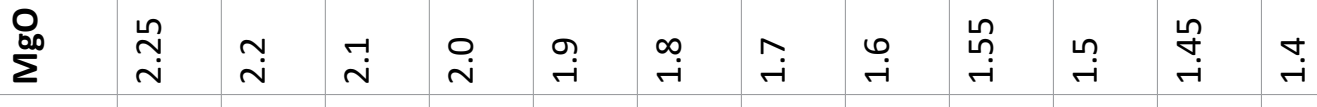

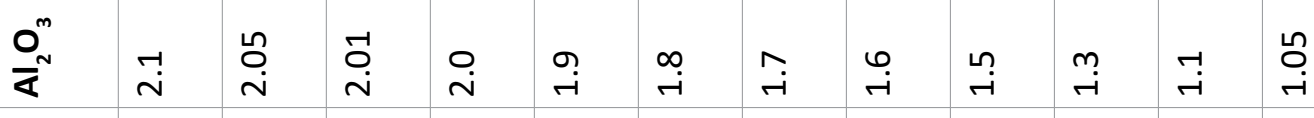

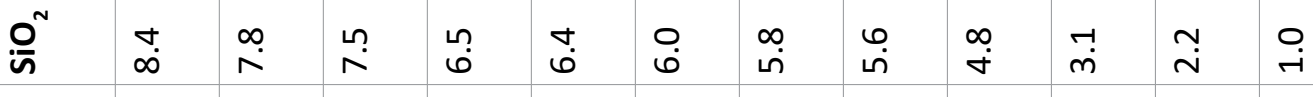

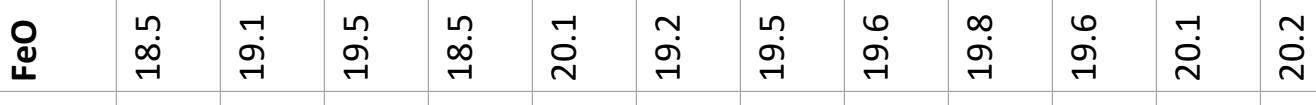

要

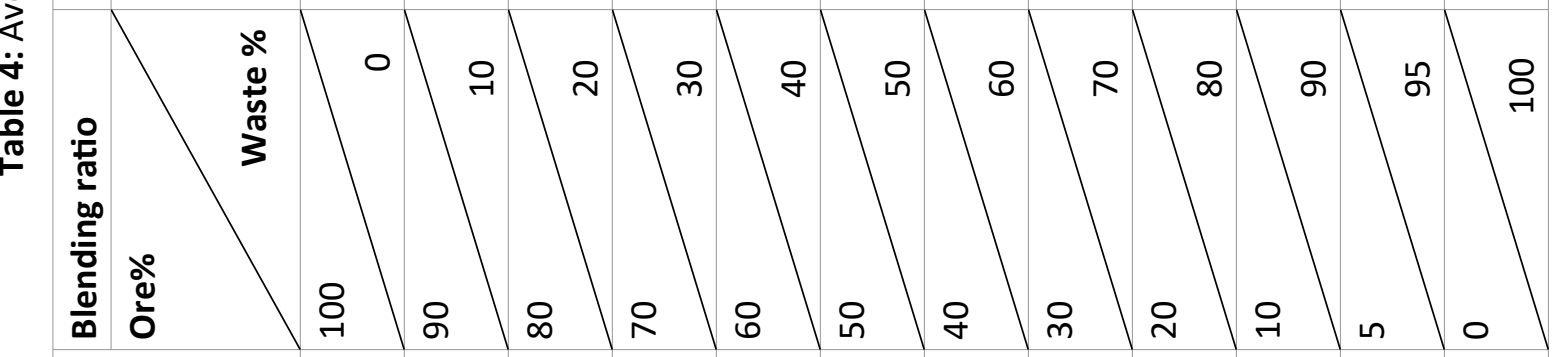

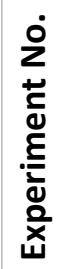


Table 5: Chemical composition of the oxide fine and the sludge.

\begin{tabular}{|l|l|l|l|l|l|l|l|l|l|l|l|l|}
\hline El-Bahareya Ores (B.O.) & 100 & 90 & 80 & 70 & 60 & 50 & 40 & 30 & 2 & 10 & 5 & 0 \\
\hline Waste Material (W.M.) & 0 & 10 & 20 & 30 & 40 & 50 & 60 & 70 & 80 & 90 & 95 & 100 \\
\hline
\end{tabular}

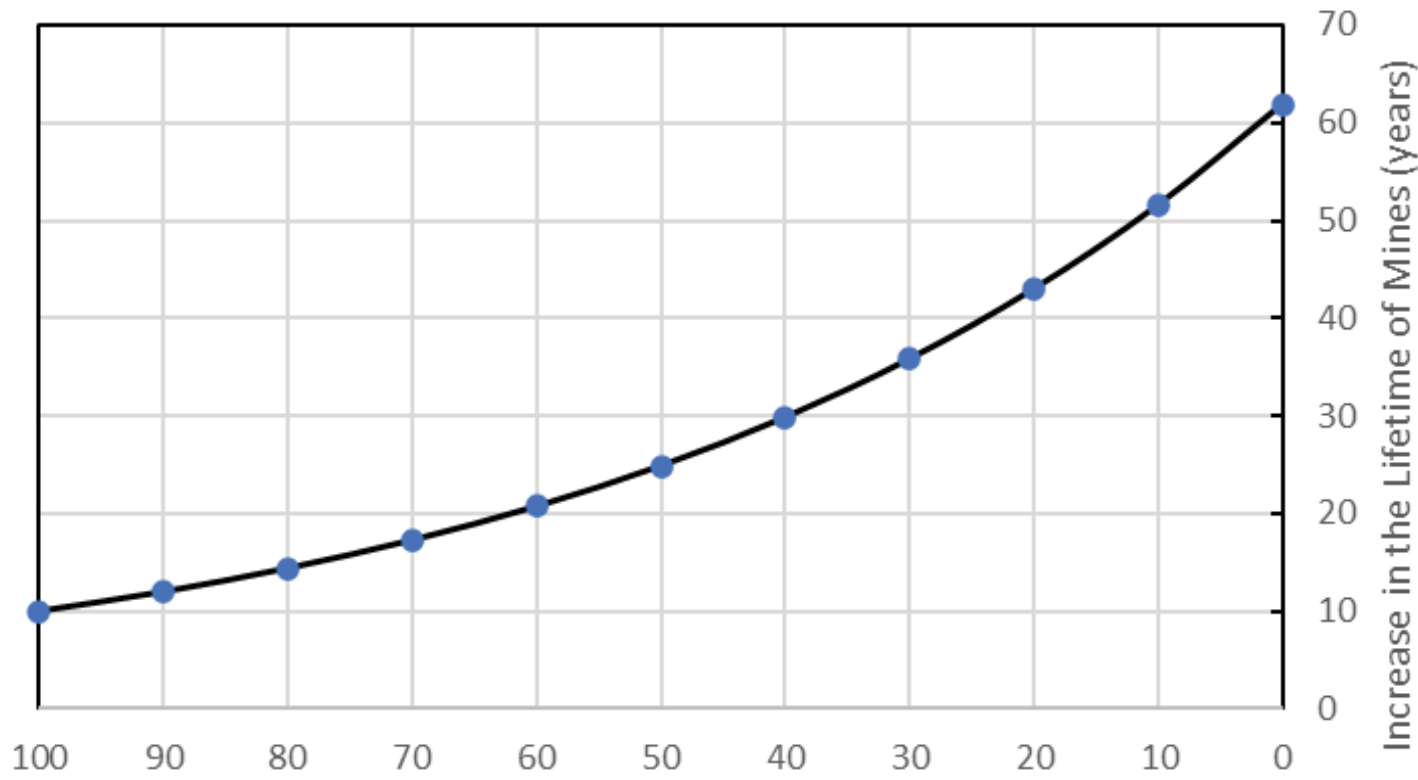

Blending Ratio (Ore \%)

Figure 5: Increase in the lifetime of mines (years).

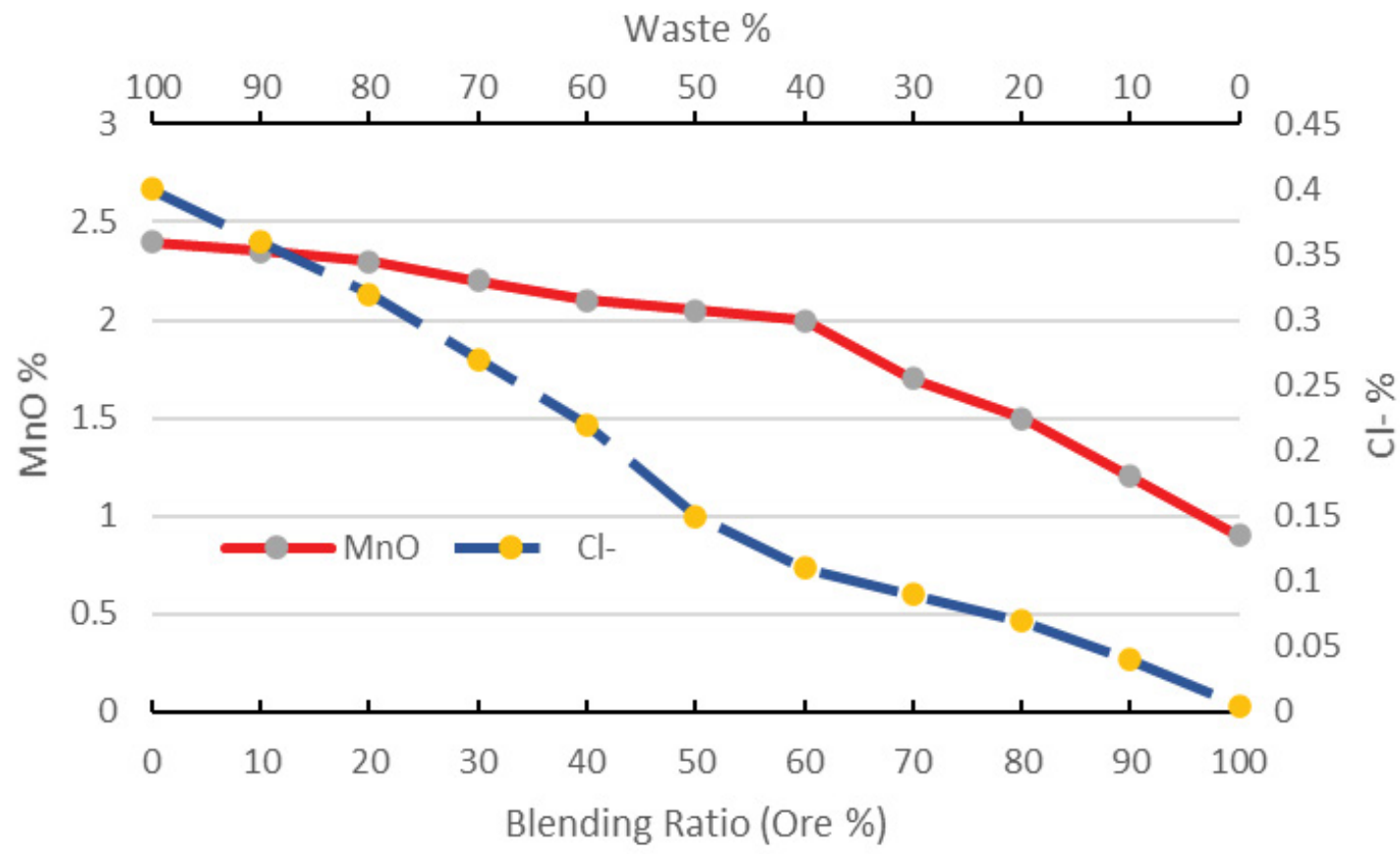

Figure 6: Change in $\mathrm{Cl}-\%$ and $\mathrm{MnO} \%$ vs. blending ratio.

corrosion resulting from chlorides in the waste gases.

It is highly recommended to perform industrialscale experiments for the sintering charges using different blends of the $70 \%-30 \%$ waste with different percentages of calcareous mud [29]. This will be the subject of a forthcoming publication. 


\section{References}

1. Upadhyaya GS (2009) Sintering Fundamentals. Trans Tech Publications, Switzerland.

2. Fang ZZ (2010) Sintering of advanced materials: Fundamentals and processes. Woodhead Publishing Limited.

3. Fernández-González D, Ruiz-Bustinza I, Mochón J, González-Gasca C, Verdeja LF (2017) Iron ore sintering: Process. Mineral Processing and Extractive Metallurgy Review 38: 215-227.

4. Volodymyr S (2012) Sintering: Methods and products. In: Tech, Janeza Trdine, Croatia.

5. Javier M, Alejandro C, Íñigo RB, Luis FV, Robla JI, et al. (2014) Iron ore sintering Part 2: Quality indices and productivity. Dyna 81: 168-177.

6. Dharm JG, Qingshi S, Allert A, Jan van der S, Jilt S, et al. (2020) Ferrous burden behaviour under nut coke mixed charge conditions. Ironmaking \& Steelmaking 47: 1114-1126.

7. Pal J, Ghorai S, Venkatesh P, Goswami MC, Bandyopadhyay D, et al. (2013) Development of fluxed micropellets for sintering utilising iron oxide waste fines. Ironmaking and Steelmaking 40: 498-505.

8. Gavel DJ, Ademab A, Stel J, Peetersb T, Sietsmaa J, et al. (2021) A comparative study of pellets, sinter and mixed ferrous burden behaviour under simulated blast furnace condition. Ironmaking \& Steelmaking 48: 359-369.

9. Srinivasan NS, Staffansson LL (1990) A theoretical analysis of the fluidized-bed process for the reduction of iron ores. Chemical Engineering Science 45: 12531265.

10.Zhou M, Yu Z, Wang P, Xie H, Wen Y, et al. (2020) Thermodynamic analysis of iron ore sintering process based on biomass carbon. Energies 13: 5988.

11.Nicol S, Chen J, Qi W, Mao X, Jak E, et al. (2019) Measurement of process conditions present in pilot scale iron ore sintering. Minerals 9: 374.

12.Gavel DJ, Song Q, Adema A, Stel J, Sietsma J, et al. (2020) Characterization of the burden behaviour of iron ore pellets mixed with nut coke under simulated blast furnace conditions. Ironmaking \& Steelmaking 47: 195-202.

13. Davies J, Moon JT, Traice FB (1978) Alkalis in the blast furnace. Ironmaking and Steelmaking 4: 151-161.

14.UCE, USS Engineering and Consultants INC (1979) Operations improvement study egyptian iron and steel company. Proj 4749-1, Final Report.
15. Rassoul SA (1985) Submitted to the supreme council of the Egyptian Universities. Report No. 4.

16. Hassan AS (2015) Addition of secondary by-products of EZDK (Hadid Ezz) to the sintering charge. EZDK Report.

17. Rassoul EMA, Wilder D (1985) Towards better utilization of raw materials and energy in the metallurgical industry in Egypt. Annual Report.

18. Rassoul SM, El-Nabawi M, Doheim MA (1973) Sintering of El-Bahariya iron ores. Proc of the 7th Arab Sc Congr Cairo, Egypt, 379-394.

19.El-Hussiny NA, Mohamed FM, Shalabi MEH (2011) Recycling of mill scale in sintering process. Science of Sintering 43: 21-31.

20.Botha PA (1993) Iron-ore sinter produced from a mix containing waste materials. JS Afr Inst Min Metall 93: 13-19.

21.Abderrassoul RA, Rassoul EMA (1996) Egypt's natural resources management. Fifth International Symposium of the Engineering Management Society, Egypt.

22.Andersson A (2019) Recycling of blast furnace sludge within the integrated steel plant: Potential for complete recycling and influence on operation. Doctoral Thesis, Luleå University of Technology.

23. Nyquist O (1962) Agglomeration. In: Knepper W, Intersc Publ, 809.

24.Singh PK, Kumar AL, Katiyar PK, Maurya R (2017) Agglomeration behaviour of steel plants solid waste and its effect on sintering performance. Journal of Materials Research and Technology 6: 289-296.

25.Pokhfesnef AN, Rassoul SA, Vegman EF (1962) Isv. Vish. Uch. Chornia Metalurgia 7: 30.

26. Egyptian Geological Survey Authority, Personal Communication.

27.Abdel-Hamid AA, SMA Rassoul (1989) Effect and behaviour of alkalines in blast furnaces. Proc. Developments in Production Engineering Design and Control, 4th Alexandria University PEDAC'89, Alexandria, Egypt, 27-29.

28. Bogdandy L, Scmolke R (1957) The production of fine ore agglomerates and their behavior in the blast furance. Stahl \& Eisen 77: 685-693.

29. Rassoul EMA, Rassoul RA (2020) Comparative study of some alternatives for the reuse of calcareous mud in Egypt. Int J Metall Met Phys 5: 049. 